\title{
On the shoulders of idiots
}

\section{Re-thinking science communication as 'event'}

Horst, Maja; Michael, Mike

Published in:

Science as Culture

DOI:

10.1080/09505431.2010.524199

Publication date:

2011

Document version

Early version, also known as pre-print

Citation for published version (APA):

Horst, M., \& Michael, M. (2011). On the shoulders of idiots: Re-thinking science communication as 'event'. Science as Culture, 20(3), 283-306. https://doi.org/10.1080/09505431.2010.524199 
On the shoulders of idiots:

Re-thinking science communication as 'event'

Maja Horst \& Mike Michael

To be published in Science as Culture 


\title{
On the shoulders of idiots:
}

\section{Rethinking science communication as 'event'}

\begin{abstract}
Characterised by a shift from a diffusion to a deliberation model of science communication, the past decades have witnessed a proliferation of science communication formats. In order to better understand the complexity and novelty of these formats, we propose a 'model of emergence' that conceptualises science communication as an event in which the event itself, as well as the various actors that contribute to it, are emergent. To operationalize this model of emergence, we use Isabelle Stengers' figure of the idiot as an analytical tool which lets us interrogate our own implicit assumptions about science communication and the way they shape interactions in specific communication events. This makes it possible to be more sensitive to the ways in which we enable the emergence of particular identities and audience reactions, but also how we understand the role of science communicators themselves. A recent experiment with a science communication installation, 'The Landscape of Expectations', is used as an example that lets us trace how the 'idiotic behaviours' of visitors, which on one level make no sense, enable us to query presuppositions about the repertoire of behaviours available to the public and the assumed relations of power between experts and laypeople.
\end{abstract}




\section{Introduction}

In September 2007 a social science researcher was standing in a shopping centre outside Copenhagen watching Saturday morning shoppers interact with a science communication installation that she had made in collaboration with a spatial designer. The theme of the installation was taken from her research about public controversies over emerging science and technology, and she had made the installation in order to 'take her own medicine' and try to engage in dialogue with audiences. However, as she stood there watching the shoppers interact with the installation in a number of ways that she and the designer had not foreseen, she wondered how to interpret these additional contributions. The installation was designed to accommodate many different audience reactions and to be as inclusive as possible in its address to by-passers. Yet, some members of the Saturday morning crowd seemed to find unanticipated ways of interacting with the installation. For the social scientist, a new problem crystallised: How could she make sense of these unexpected engagements? Should they just be ignored as falling outside the experiment or did they suggest something more fundamental about science communication?

The following is an effort to account for the way in which the installation was designed to be inclusive yet also enabling audiences to challenge it in unforeseen ways. In the process, we consider how their various unanticipated and 'idiotic' behaviours serve to trouble the very exercise of science communication and public engagement about science and technology. More specifically, we critically draw on the literature on science communication, paying particular attention to the performative aspects of experiments with dialogical forms and the ways in which they produce particular realities but also open up new insights. The argument is that we need to think of instances of science communication as 'events', which mix and momentarily fix a number of different elements and perceptions. The event itself is understood as productive because the mixing of all these relations is what produces the entity ‘science communication' and, 
simultaneously, the science communication event shapes those entities that have entered into it (including the public, children, and the communicators themselves). The upshot of this is that we hope to develop a more productive grasp of what happens in the science communication event, not least when it entails forms of engagement that develop in unforeseen directions.

In order to advance this framework, we will start with an account of science communication and identify three different models for thinking about the flow of communication: diffusion, deliberation and emergence. Investigating the model of emergence further, we consider the implications of describing science communication as an event and introduce the notion of ‘idiotic behaviour' as an analytical tool which enables us critically to reflect on our own taken for granted, constitutive assumptions. Following this, we present the installation experiment and offer some examples of the use of dialogical forms of engagement. In the subsequent section, we focus on the use of the idiotic behaviour as an analytical tool, which allows us to make sense of unexpected reactions to the experiment. The purpose is to facilitate a renewed understanding of how identities emerge in the event of science communication in productive ways. We conclude with a discussion of some of the broader implications of the event perspective for science communication and public engagement processes.

\section{Three models of science communication}

It is possible to identify several models for the communicative relationship between science and society in the literature on science communication and public understanding of science (Horst, 2008a). Traditional PUS subscribes to what can be called a typical diffusion model, in which knowledge and information about science is supposed to be diffused from science via some medium to an audience (Rogers, 1995). Ethnographic, or critical, PUS has criticised this model, arguing that 
the problem is not so much that the public does not listen to science, but rather that science does not understand the ways in which the publics (in their many diverse and heterogeneous forms) make sense of science, as well as produce relevant and useful knowledge in their own right (Irwin \& Wynne, 1996). Critical PUS therefore, often emphasises the need for public deliberation and a communication flow from the public towards science, which could transform science and scientists such that they are more in accordance with society (Wilsdon et al. 2005; Einsiedel et al, 2001; Fischer, 1999; Irwin, 1995; Joss, 1999).

Importantly, while the critical PUS model is sensitive to difference and diversity amongst publics, it has nevertheless operated with a particular model of the public, one in which the public remains juxtaposed to science and is viewed in terms of relations of trust or cultural identity (see discussions in Michael, 2002 \& Horst 2008a). The introduction of deliberation and dialogue in various engagement exercises inspired by critical PUS has thus often served a specific purpose, such as the democratisation of science governance or the formation of robust policies for science and technology. So, despite the talk of dialogue as a two-way communication process, the outcomes of dialogues have often implied a receiver in science. Furthermore, insofar as critical PUS laid emphasis on the means by which science communication allows space for the voice of the public, it usually focused upon the formal procedures by which such communication can be enacted (Edwards, 1999; Einsiedel \& Eastlick, 2000; Joss, 2002; Andersen \& Jæger, 1999).

So, despite their differences, the traditional (diffusion) and the critical (deliberation) model of science communication seem to share an understanding of science communication as an event in which science and society come into contact through a medium. We note how both of these models predominantly assumed this medium to be a stable ‘intermediary’ (Latour, 1987) for transporting the knowledge which will bring about the desired effects. Following Latour we use the term intermediary to designate the idea of a stable form through which it is possible to relay 
information or social relations, without these or the intermediary being transformed in the process. The crucial difference between the two models (diffusion and deliberation) was therefore not the perception of the use of a medium, but rather the direction of the flow of information, knowledge and values.

However, further scrutiny of more recent studies in critically-inflected PUS now points to a third model of the communicative relationship between science and society (Lezaun \& Soneryd, 2007; Jensen, 2005; Irwin \& Michael, 2003; Michael, 2002). Rather than conceptualising communication as a flow of knowledge or values from one party to another, it is seen as a constitutive force in shaping entities such as science, publics and society. This third model of emergence abstains from broad reifications of these, but argues that specific instances of science communication will establish these entities temporarily. Crucial here is the principle that there is no privileged direction of information as in the other two models. It is through the process of science communication that it becomes possible to approach an identification of a public and a science as well as a communicative relationship between them. Neither is there any stable medium, which functions as an intermediary for the flow of knowledge and information. The entities themselves are seen as mediators, that is, as actants who change, and are changed through, the event of coming together. Likewise, there is no separate entity which can be identified as communication. We should therefore not study science communication as a separate topic, but understand communication as part and parcel of science, publics and society in the making (Latour 1987).

\section{The model of emergence, the event, and the idiot}

For the purposes of the present paper it is important to clarify the concept of event as it applies to the model of emergence. All instances of communication can of course, be perceived as an event, 
but in the model of emergence the event of science communication is understood in terms of the coming together of different elements through which novel relations and identities can emerge. Clearly, this requires a reorientation that is sensitive to the ways in which our preconceptions of science communication shape our ability to understand the event, its outcomes and its challenges.

In order to demonstrate how this sensitivity can be developed and operationalised, we draw upon Mariam Fraser's (2010) excellent discussion of the development of the concept of event in Whitehead, Stengers and Deleuze. At base, we regard the event as an actual occasion comprised of the coming together of numerous entities that are social and material, human and nonhuman, macro and micro, cognitive and affective, available and unavailable to consciousness. These entities, in coming together, make the event. However, as Fraser notes, for Gilles Deleuze, we can also view the event as a moment where these entities rather than simply 'being together', also 'become together'. As such, the event is characterised by the fact that the interactions of its constitutive elements change those elements. Thus, in the case of the event of science communication, both science and society become - that is, emerge - as more or less changed. The value of such a conception of the event derives from its capacity to generate the new. The corollary is that we become analytically sensitive to such novelty, querying the usual reading of an event such as science communication. In the process, we can begin to trace new possibilities for action and understanding brought about by the event. Rather than seek solutions to the problems of communication (by asking questions about how science might be better communicated and how we can interest the uninterested), we can begin to rethink communication itself (and investigate what communication means in such an event and how the audience, including the uninterested, shape the communicator). With this notion of event in place, we can move from instrumental solutions to what Fraser articulates as 'inventive problem-making'. As we have hinted, such inventive problemmaking folds back onto the analyst of the event who undergoes a 'transformation of the will' such 
that, to paraphrase Fraser, both the analyst of, and the participant in, the event of science communication are likely to be transformed.

In the preceding paragraph we made deliberate mention of the uninterested. This is because a key figure for us in the analysis of the event of science communication is what Isabelle Stengers calls 'the idiot'. For Stengers, the idiot is the non-participant - an ever-present spectre who, by refusing the invitation to the event, and not bothering to explain that refusal (ie operating with incommensurable criteria of what is sensible/meaningful), makes us critically reflect on 'what we are busy doing' - indeed it 'suspends the habits that make us believe that we know what we know and who we are, that we hold the meaning of what makes us exist' (Stengers, 2005, p.1003). The idiot is at once absent (it can't be bothered to contribute meaningfully) and present (it hangs around on the sidelines). Its absence enables meanings to be transferred as usual, yet our awareness of its absence, or indeed our practical efforts to exclude it, render it present, and that presence is disruptive, perturbing the processes of communication (or order-making). ${ }^{\mathrm{i}}$

Stengers' idiot is a metaphysical principle through which we can query, albeit in the abstract, our own taken for granted, constitutive assumptions. Yet, in the context of interrogating specific science communication events we must operationalise this figure and we need to do so in a way that does not make us re-introduce a notion of publics or audiences as being un-informed or stupid (the public as idiots in the usual sense, as opposed to our technical meaning of that term). We will do so by talking about 'idiotic behaviour' which we use as an analytical concept for those reactions which appear alien, confusing or disruptive to the design of the science communication event, that is, those actions which are not sensible (in the sense of making no sense) in the particular context of that event. Idiotic behaviour thus indexes those actions which make no accessible contribution according to the original intent behind the particular science communication exercise and therefore are most readily understood as non-engagement. The point is that such idiotic 
behaviour introduces noise into the design, planning and interpretation of the event, and this is exactly what makes it valuable. If we are to understand how the event of science communication allows identities to emerge, we need an analytical tool which makes us sensitive towards the shaping process of the event itself, to the way that identities emerge in unexpected ways and challenge the interpretative constraints we impose on the event. Crucially, the notion of idiotic behaviour enables us to use the noise to do inventive problem-making - to rethink the event, to complexify it, and in the process to take fright at our self-assurance and open up the potential for a 'transformation of the will'. ii

In what follows, we will describe a particular science communication event, reflecting on how idiotic behaviour was initially rendered excluded - made absent from the account as a way of making the event comprehensible. However, we then go on to rethink the science communication event in light of those very actions - to explore how we can reconfigure our grasp of what it means to do science communication. We thus aspire not only to stand on the shoulders of the giants of science communication, but also on the shoulders of its idiots.

\section{An experiment with science communication}

The experiment with the science communication installation was funded by the Danish Research Council for Humanities and it was designed to communicate social scientific research on the Danish public debate about biotechnology in a spatial installation, thereby allowing publics to participate and engage in dialogue about the issues. It should be immediately stated that we use the word experiment here in a broad sense to denote the act of trying something out, not in the stricter sense as a scientific experiment to test a specific hypothesis under controlled conditions. The experiment 
we discuss here was characterised primarily as an effort to make an intervention and see what would happen. It was, however, guided by four basic 'rules of engagement':

- The installation should make the communication dialogical and interactive and this should be the prime focus. The design process of the installation had dialogue as a core parameter: dialogue would thus not be treated as an optional add-on to the communication of scientific knowledge. In many science communication endeavours, there is an expectation that publics first let themselves be informed by the facts so that they are able to take part in a dialogue about science and technology. By contrast, the aim in the present experiment was to avoid this kind of entry barrier and make the invitation to engagement as unconditional of scientific knowledge as possible.

- The installation should seek to communicate research-based problematics, rather than readymade packages of knowledge. The basis of this ambition was a conviction that it can be difficult to create dialogue and participation around a discussion of stable and uncontroversial facts. Once a phenomenon is conceived of as a fact it has become stabilised (Latour \& Woolgar, 1979) in a way that might close off dialogue rather than open it up. If the objective is to engage researchers and their publics in dialogue with the aim that both parties will learn from the encounter, the debate has to be focused on issues where researchers are open to input and suggestions, for instance concerning research problems.

- $\quad$ The installation should be conceived as an effort to communicate with more than words. Language is a medium with which most researchers and scientists are very comfortable, but this comfort is not universally shared in society. Social science, in particular, is haunted by an almost exclusive focus upon words as the medium of communication. In order to try to break this pattern the aim was to create a spatial installation, which should communicate in spatial, kinaesthetic and tactile ways, rather than just addressing the verbal capacity of the intellect. 
- The installation should create engagement, irritation or curiosity rather than just

understanding. A central concern within the discussions of public engagement with science is whether dialogue is just another way of trying to get the public to consent to traditional scientific development (Hagendijk \& Irwin, 2006; Levidow \& Marris, 2001; Wynne, 2005). Whereas understanding is often a justifiable objective, the idea with this specific exercise was to accept that publics should not be guided towards a specific goal, for instance understanding. Rather, it should be an open invitation to engage and interact in ways that seemed meaningful to the visitors themselves.

Based upon these rules of engagement, the objective was to create a spatial installation, which could be placed in public in order to invite passers-by to participate in debate and reflection about the regulation of, and expectations towards, new technology. The theme of the installation was taken from research on the public debate about biotechnology in Denmark (Horst, 2003; 2005; 2007; 2008b). Inspired by various strands in the literature on Science and Technology Studies, the basic goal was to invite dialogue about the ethical, social, economic and cultural consequences of research and new technology, thereby increasing visitors' sensitivity towards the social shaping of new technologies and their own participation in these processes.

The creation of the installation was conducted through an iterative process which demanded very close collaboration between the researcher and the designer. Key aspects of the social science were identified and translated into conceptual models through the use of a number of visualisation and spatialisation techniques. During this development, the rules of engagement, however, had to be re-thought. Most importantly, it became obvious that it was necessary to think more purposefully about the ways in which the installation would invite visitors to engage in dialogue. In order for visitors to be able to interact with the installation, it needed to have some 
form of message with which to engage. Inspired by the social science input, the message was formulated as: Technological possibilities do not fall from the sky. They are created within and shaped by social processes characterised by conflict, in which you have the possibility of participating. During the design phase, the focus was on making this message intelligible and the creative work was primarily undertaken along the lines of the model of dissemination described above. Subsequently, the ideals of dialogue, engagement and opening up were put in focus in the phase of exhibition. In this way the creation of the installation challenged an understanding of the models of science communication as incommensurably or ideologically distinct. Rather this experience suggests that the models serve to highlight particular aspects of a given practice and that, as analytical tools, they contribute more by being considered in combination than if they are used as separate and foundational normative decrees.

\section{The Landscape of Expectations}

The experimentation resulted in an installation of approximately $35 \mathrm{~m}^{2}$, entitled "Landscape of Expectations" (see also www.stamcellenetvaerket.dk). Physically, it consisted of 21 big boxes placed in a spiral form. The exterior offered a visual display of different discourses in the form of expectations and attitudes towards science and technology. The inside of the installation consisted of interactive elements, where the visitors could engage in different ways. The installation was created in the spring of 2007 and was exhibited in different public arenas in 2007 and 2008. For present purposes, the most interesting exhibition was the one that took place in the shopping centre outside Copenhagen in September 2007, where the installation was open to the public for two days. This exhibition was intended to subject the installation to a basic test, or experiment, to see whether it worked as imagined: is it possible to create dialogue and participation with a spatial installation? 
The installation was therefore exhibited without any additional meta-communication and although both researcher and designer were present in the shopping centre during the exhibition, we were anonymous and not visibly connected to the installation. The primary documentation from this exhibition is therefore derived from the registration of the physical traces of the interactions and other signs left by visitors as well as passive observation through surveillance cameras in the installation.

The exterior of the installation was designed to represent four different discourses about the role of science in society with various types of images and statements. The discourses were originally identified through an analysis of Danish news coverage (Horst, 2003; 2005; 2007) inspired by Mary Douglas (1996a; 1996b; 2001; Douglas \& Wildavsky, 1983) and in the installation each of them had its own visual expression in terms of colours, types of images and use of language. The discourse of 'Hierarchy' portrays science as an, ideally, independent institution in society guided by its own internal rules and norms in order to produce true knowledge about the world. In the installation this discourse was displayed in blue through pictures from cell cultures and laboratories coupled with columns of words like 'system', 'truth', 'knowledge', 'order', ‘structure’, ‘classification’ (see picture 1 - photographs by Mads Folmer). The discourse of 'Market' revolves around an understanding of science as a useful resource in society and a notion that regulation of science should be based on a compromise between the interests of various relevant actors. This discourse was visualised in red with a number of various statements about the usefulness of science, on top of which there were four figures each expressing their own interest in scientific progress. A third discourse revolves around the notion that although scientific development looks like progress, it really is degradation, corruption of true values and loss of humanity. This discourse was called 'the Sect' and displayed in two-layered pictures. The top layer was a naturalistic picture, but cut away at a certain point to reveal the underlying, robotic, black- 
and-white and frightening version of the same image. Finally, a fourth discourse is characterised by a lack of belief in the value of systematic production of knowledge as well as the ability to control science for the greater good. This discourse was named 'the Islands' and consisted of incongruent statements like 'I don't believe in them', 'they are going to do what they want anyway' and 'is this going to save my uncle?’

In the context of the shopping centre, the exterior of the installation appeared rather different from the surrounding shop facades as it seemed less glossy and commercial, and more educational and 'hand-painted'. In this way it stood out quite distinctly and it drew the initial attention of almost all passers-by. In particular, younger men examined the installation for long periods of time, whereas women in general seemed less inclined to stop and investigate the installation further.

At the entrance of the installation there was a TV screen which constantly replayed a $1 \frac{1}{2}$ minute video in which a well-known Danish science-TV presenter was introducing the installation and inviting people inside (see picture 2). There was also a sign which stated that

- the installation was an experiment in social science communication created with funding from Copenhagen Business School and the Research Council,

- there were surveillance cameras installed

- children below 12 should be accompanied by an adult.

At the entrance there was also a small leaflet explaining the project, but apart from this the installation was left to speak for itself. There were two 'surveillance cameras' placed in the installation in order to facilitate the recording of visitors' interactions necessary for subsequent analysis. We used the term surveillance to signify the constant video-recording to the audience, and 
one of these cameras was also feeding directly to a video screen on the outside of the installation. The original intention with this live-feed was to create curiosity in passers-by but it would also have the effect of making the use of surveillance cameras explicitly visible. This turned out to be a relevant precaution as it became clear that not everybody would read the notice mentioned above. Many visitors seemed to go directly into the installation to explore its content, rather than trying to figure it out from the TV-presentation or the written notice. Some visitors, however, would listen to the TV-presentation and then peer through the entrance, but not enter to experience the installation for themselves. Often visitors came in small groups and would interpret meanings and form opinions together in a joint process of action and discussion. Many children visited the installation and often they brought their parents, but the notice about children below 12 having to be accompanied by an adult was routinely disregarded. It is clear from the surveillance tapes that the children in general would engage physically with the installation in a much more immediate way than the adults. Children were quick to pick elements up and play with them - sometimes doing it the way it was intended, but quite often inventing new ways. Adults would usually be more hesitant and start by connecting to the interactive elements that included text and only subsequently engage with other elements.

Looking into the middle of the installation, the first feature to catch the eye was a table-like feature divided into quarters. Upon each of these quarters a specific structure was built using one of four different sets of building blocks. The four types of blocks were related to the four discourses on display and visitors were invited to participate in the building with an abundance of additional building blocks. Hierarchical building blocks were wooden cubes and pegs which meant that they could only be assembled in a very particular grated structure (see picture 3). Market building blocks were sticks in various colours, lengths and widths all having at least 3 different points of Velcro on them, which meant that they could be assembled in many ways. Sectarian 
building blocks were stone-like figures with holes through them and an elastic band to connect them to each other. Finally the Island blocks were foam plates that could be built together and contained various holes in which different sized wooden blocks would fit. In the entrance video, people were encouraged to participate in the 'building of society' in the middle, and although this video only captured the attention of a minority of the visitors entering, many visitors would take the opportunity to build with a few of the blocks at some point during their visit. In particular, however, children and teenage boys spent a long time building and created quite elaborate structures.

The remainder of the interactive interior consisted of a number of different elements which were designed to invite the visitors to participate in a discussion of the role of science and technology in society. In combination they were intended to demonstrate how the shaping of emerging science and technology takes place in a social setting, where creation of public acceptance, distribution of resources etc. makes a difference to which type of technology it is possible to create. Most of the interactive elements were constructed on the wooden boxes that formed the spiral, and organised so that each box represented one element. In the context of this paper, we only have space for describing some of these elements in detail.

Some boxes presented visitors with questions such as: 'What is the role of science in shaping future society?' 'How should we spend societal resources?' Each question had some predefined answers and different ways for visitors to physically indicate what they thought were the best answers. There was also space for visitors to construct their own answer-categories. For example, one of the boxes asked visitors: 'Who should control the development and use of new technology?' The pre-shaped answer-categories were Researchers, Politicians, Business, and Citizens, and visitors made their choice by moving a light-switch to either a green light (yes) or a red light (no) for each of these categories (see picture 4). At the shopping centre exhibition, the business light tended to be red, indicating a resistance among visitors to the idea that business actors 
should be controlling development and use of technology. Meanwhile the other three preconceived categories shifted rather regularly between green and red, indicating no clear pattern of preferences among visitors on who should control this area. Furthermore, the option of adding alternative answers was frequently taken up and suggestions for alternative (groups of) actors ranged across: 'informed citizens', 'lemmings’, ‘children', ‘us', ‘me’, ‘the new generation', 'humans’, ‘the world’, and various names such as Martin, Mik and Danixs.

Visitors were encouraged to register their answers by putting voting beads in transparent cylinders. In most of the exhibits it was left to visitors to decide how many beads they would put in each cylinder and due to the physical design, we could not prevent them from taking beads out of the cylinders. Originally, the plan was to make the voting system more controlled - as in 'one person, one vote' - but this was technically too complex to achieve. It was also more interesting to use the voting system as an opportunity for individual reflection rather than as a system for gauging public opinion. The idea was therefore to make visitors reflect on the action of voting. For instance we hoped to encourage visitors to consider the relation between their own and other peoples' votes. At the exhibition in the shopping centre, visitors would vote in various ways, but in general it is difficult to assess how they made sense of this activity.

One incident in the above-mentioned element about control of new technology, however, directly suggests a reflection about the voting system. At some point one of the visitors had removed all the voting beads from the Business cylinder and placed them in the Citizens cylinder $^{\text {iii }}$. The immediate consequence was that the votes seemed to demonstrate a strong preference for having citizens and not business exercise control over the development and use of new technologies, but this impression was brought about by an action, which at first was interpreted as 'tampering with the votes', because the person had moved votes cast by other visitors. However, on reflection, the most interesting thing about this instance might not be the actual 'tampering' with 
the votes, but rather the fact that no one else did the same thing. In later discussions with various academics and stakeholders, it has been suggested that it might be an important characteristic of the Danes (or Scandinavians) that they seem predominantly to adhere to a one-person-one-vote principle, even when they are at liberty not to do so.

Other interactive elements were focused on individual reflections. One was about expectations towards the future. Visitors could go into this box, where two walls consisted of mirrors covered with transparent images of either hope or fear. The light was changing in the box, which meant that visitors would alternately experience their own reflections and the hope-fear images clearest. At the adjoining box, visitors were asked to write their hopes on green notes and their fears on red notes and hang them on a set of strings for others to see (see picture 5).

Another set of boxes consisted of many small slates where visitors could write their own statements as well as read and (un)cover other visitor statements (see picture 6). The intention behind this feature was to simulate something like public debate as it is expressed in various media. The statements were not deleted between exhibitions and they could therefore be seen to establish interaction between contexts separated in time and space. One example was a statement which read: 'Let researchers use their knowledge', which was written before the shopping centre exhibition. In the shopping centre someone wrote below: 'let's have a minister for research, who cares about research $^{\text {iv }}$. At a later point in time, a visitor underlined both statements and subsequently another wrote 'me' below the latter statement. These expressions can of course be evaluated in different ways, and it is impossible to know whether the 'me' was meant as a political statement, an ironic comment, both of these, or something entirely different. In general, many of the statements were related to the issues of expectations and regulation of science and technology, but there were also a large number of various statements as well as drawings and names - many of them clearly inspired by graffiti and tags - which seemed unrelated to the general theme. One example of this was the 
symbol '69' which has commonly been used as a tag all over Copenhagen as a protest towards the demolition of the so called 'Youth House' in March 2007 .

In this way, the display of statements demonstrates the heterogeneity of public discourse. It is possible to argue that there are connections or affinities in the protest towards the demolition of the underground scene in the youth house and a general critique of technological development. But it is equally possible that the sign 69 is just left as a mark irrespective of the context and that it thereby demonstrates the ruptures or disconnectedness of public discourse. Crucial, however, is the fact that the collection of statements does not necessarily equal proof of 'a public debate'. The fact that someone has uttered/left a statement does not mean that it is noticed or taken into account by anybody else. This is also a fundamental insight within the analysis, since it is the observer who has to decide whether to decode (Hall, 1980) the collection of statements as an expression of public debate.

In the context of the installation, however, it is not vital to make a distinction between the intent of different subjects in encoding and decoding the messages and statements. The objective was not to gauge opinions in order to be able to summarise what people (for instance the Danish shopping centre visitor population) 'really' think about the role of science and technology in society. Rather, the objective was to create participation in itself, because the act of participation was, in a crucial sense, the message. It was in the experience of participation that visitors performed the message of the installation. When they chose to engage with the installation, they were simultaneously adding to the display of opinion formation about expectations towards science and technology. Moreover, they would leave traces which could influence subsequent visitors. In this way, they were demonstrating by their actions how the shaping of expectations towards emerging science and technology might take place in a social setting. 
This short recapitulation of the experiences with the installation, therefore, demonstrates an interconnectedness of the three models of science communication mentioned previously. Perhaps not unsurprisingly, it turned out to be necessary to think in terms of the model of diffusion, when creating the installation. The social scientist and spatial communicator had a message which they wanted the installation to convey to its visitors and they had to work hard to make this message intelligible. At the same time, however, the installation was originally conceived as a way of engaging visitors in dialogue and the actual exhibition of the installation was guided by the model of deliberation in trying to invite visitors to participate. However, the third model of emergence is relevant when we try to step back from the installation and reflect on what we learn through its enactment. The last issue is therefore to consider how the exhibition of the installation performed an event in which identities were shaped and entered into contact in a way that allowed the researcher and the designer to learn something new. In the remaining section we will turn to this discussion. We will demonstrate how it is possible to learn from the event about our taken-forgranted assumptions of what such an experiment with spatial science communication is and should be, by using our analytical framework of understanding the performativity of an event through the figure of 'idiotic behaviour'.

\section{Learning from 'idiotic behaviour'}

Throughout the exhibition in the shopping centre there were a number of instances where visitors did not behave according to what was imagined in the creation of the installation. In this section we try to analyse some of these reactions with the help of the analytical trope of idiotic behaviour. It is of course provoking to call these actions 'idiotic' and it should be emphasized that we do not use this analytical concept as an insult towards the people who performed them. In fact, our aim is 
exactly the opposite: to try to include these actions in the analysis, rather than exclude them as irrational, although the latter was the initial reaction to their strangeness. It should also be underlined that there is a large zone of indifference between what could be called idiotic and nonidiotic responses and the previous section has mentioned several examples of actions, which were definitely not expected by the creators of the installation. On this basis, the following is not an exhaustive list of idiotic responses, but rather some selected examples which illustrate the types of learning that can be elicited from the use of the idiot as analytical figure.

As mentioned previously, a video screen was installed on the outside of the installation with a direct feed from one of the surveillance cameras. The intention was to create curiosity and also to make the use of surveillance cameras visible. This choice, however, created an unintended reaction: Several groups of teenagers (primarily girls) started playing with the camera. Rather than interacting with the installation they took turns in acting in front of the camera inside while their friends would stand laughing outside looking at the video screen. At first, this behaviour engendered a sense that the installation was being misunderstood by the girls, but on thinking about this reaction through the framework of idiotic behaviour, it is obvious that this play with the camera emphasizes some implicit understandings of the role of visitors in the installation.

The reason why this reaction seemed so misplaced is because it totally broke with the configuration of visitors as citizens participating in a political debate about the regulation of science and technology, which was the framing embodied by the installation. Part of the design of the installation was directed to the tension between configurations of visitors as citizens participating in a simulation of the 'Habermasian' public sphere as opposed to consumers in a marketplace of politics. While the shopping centre exhibition had the potential to highlight this tension, it had not been foreseen that it would also generate an expression of a completely different configuration of the public space in which individual staging and performance is central. The teenagers' actions can 
be tentatively interpreted as turning the installation into a stage set for an activity modelled on current TV programmes in which normal people as amateurs receive their 15 minutes of fame by performing publicly. In this way, however, their idiotic actions illustrate how the citizenconfiguration of engagement exercises always co-exist and compete with other forms of configuration of the public space. It also points to the volatility of each of these configurations. Rather than just assume that participants in engagement exercises will share a particular configuration, it might be fruitful to consider the unavoidable interplay between these forms. It can be argued that the present installation allows for a very diverse set of enactments of participantconfigurations and that if the interpretative flexibility had been more restricted, more visitors would have comported themselves along with the dominant framing. However, it is also possible that a more rigidly denotated room would simply have meant that fewer people engaged with the installation.

Moreover, the idiotic actions that made up this particular performance of the installation point to a dimension of public engagement that most of us are tacitly aware of, but which is rarely addressed openly. This is people's capacity to be silly, to show-off, to have fun, to parody popular and elite or expert culture. To be sure there are several ways of mediating these activities through sociological discourse, but in the present context we want simply to recognize these activities (and affects) as an unexplicated part of the event of the installation. More broadly, it raises the issue of the role of mimicry, parody, play-acting, and humour in the enactment of both science communication and science. Arguably, the capacity to make fun of the seriousness in science communication comprises a resource for laypeople in their interactions with experts. Although scientists and science communicators can be seen as more powerful than audiences in the communication setting (Davies 2009), non-experts have the (quite powerful) right not to take things 
seriously. As such, the professional need of science communicators to avoid a perceived lack of seriousness might constitute a powerful factor in the design of engagement exercises and dialogue.

The play with the surveillance camera corresponded to another observation. In that particular location in the installation where visitors were asked to write their future hopes and fears (on green and red notes), several people had written things like 'my hope is to always go shopping with Tina', or 'my biggest fear is that all shopping centres in the world close'. While these statements could be interpreted as ironic comments on the installation, they could also be taken at face value to point to a very obvious insight. To a young woman on a Saturday morning, a shopping centre experience with friends might seem a lot more important and relevant than an abstract discussion of expectations towards science and emerging technology.

Reflecting further on these experiences, they point to the many different ways in which actors might choose to engage with science or debates about science, and they prompt some fundamental and crucial questions about the objectives and justifications for science communication. Although one of the objectives for doing science communication might be the noble one of enabling visitors to engage and participate in democratic decision-making on science and technology, it is important to reflect on the normative justification for, and the kinds of activities that are sidelined in realising, this ambition. Although the teenagers' focus on the camera and their own shopping experience might seem less important or serious to the science communicator, this is purely a question of perspective. Socially speaking, the visitors' apparent lack of seriousness with regard to the issues of science and democracy serves the highly serious situated enactment of their social relations within a group of girls. Indeed, to treat the installation seriously (according to a traditional perspective) would be tantamount to challenging or trivialising the social relations - of not treating the group seriously. The point is that these idiotic actions serve to make us aware of the contingency of the seriousness assumed in the science communication event. If we 
want to treat audiences symmetrically in a dialogue, we have to recognize that comportment within the installation cannot be said to be more important, serious or 'sensible' than these teenage girls' management of their internal social relations. These issues, of course, can be related to a very fundamental question of responsibilities for scientific citizenships. In the present context, we simply want to highlight that science communicators have to be aware of these issues and that it might be better to explicitly deal with them, rather than implicitly letting pre-existing norms of proper scientific citizenship shape the reaction to unanticipated behaviours.

As mentioned above, a number of the statements left in the installation were not directly linked to the issue of science and technology in any way. Like the one about fear of shopping centres closing, a number of them could be seen as ironic or as straightforwardly prioritising other issues than science and technology. However, a number of them simply did not make sense in the current setting. These included, for instance, squiggles left on a couple of the slates or a few obscenities found in various places. As the researcher anonymously patrolled the installation during the exhibition in the shopping centre, she tended to remove (when unseen by other visitors) these expressions of idiotic behaviour, because they were thought to be irrelevant or offensive to subsequent visitors.

In further hindsight the removal of these idiotic comments point to another important issue. No matter how inclusive an engagement exercise is designed to be, it is impossible not to draw a limit. Just as during the creation of the installation it was realised by the researcher and designer that they had to think in strategic terms of communicating the message, so it turned out to be impossible to escape the need to sanitize the installation in order to keep the message clear during exhibition. These realisations, however, lead to considerations of the limits to the experiment. When the researcher chooses to sanitize the installation, she breaks with the central intention behind the experiment, namely, simply to see what happens over the course of the 
installation. The acts of sanitisation thereby reveals that she is more concerned with keeping the installation as a science communication installation than letting it mutate into something else. This also makes us aware that there are two different enactments of the event aimed at two different audiences. In the first enactment, the exhibition in the shopping centre, the visitors are the obvious audience for the installation and they serve as co-creators of the message of the installation, because they enact the message through participation. However, since the researcher is also conducting the experiment as a demonstration that will subsequently be reported in writing to the Research Council as well as in papers at conferences and journals, the second enactment includes audiences of fellow PUS scholars and science communicators. Importantly, in this second enactment, the shopping centre visitors are not invited as co-creators any more. In the second enactment of the installation, the installation might best be understood as a social science laboratory, in which visitors were treated as useful objects performing a message intended for a completely different audience.

What the idiotic statements in our installation remind us is that it is impossible to avoid framing and delimitation in deliberative exercises. Perhaps, less trivially, they also point towards the need for an awareness of the organiser as a responsible actor in this framing. No matter how open and inclusive organisers try to be, they frame the event of science communication and they have to take responsibility for this framing. Whenever organisers of engagement exercises assume the role of sanitizers (as they have to) of the event of science communication, then they also must accept the responsibility for their creation of a particular form of public voice(s).

This brings us to the last example of idiotic behaviour, which in fact originated from the social scientist herself. Or rather, from that particular part of her which turned out not really to believe in the act of creating engagement. This idiotic response appeared a couple of weeks prior to the shopping centre exhibition and expressed itself as an unwillingness to participate in the exhibition. It crept in as a sneaking conviction that 'the whole set-up is silly' and an expectation that 
the outcome would be an embarrassingly visible and empty installation in the middle of a shopping centre. Taken at face value, this response was not very sensible, given that a lot of effort had been put into making this exhibition possible and that the point of the exhibition was to see whether and how the installation would work in a broad sense. Emptiness was, in this regard, also to be considered a possible outcome. But if we understand the response as a reminder that science communicators are performers too, it might make more sense. Despite the previous remarks about the responsibility of the organiser of science communication events and their discretion in framing and sanitizing public voices, such agency can be rather fragile: it is chronically dependent on the will of the audience, the visitors, the participants to play along. It is, in a word, relational.

\section{Concluding Remarks}

In this paper we have attempted to contribute to the movement of science communication beyond its embeddedness in either the diffusion or the deliberation models. By treating science communication as an event, the focus was shifted from the direction of communication between expert and lay actors to the process of mutual emergence and becoming of science communication itself, and of the various actors that enter into its enactment. Underlying this analytic move toward a model of emergence is a view that profound reflection can become a productive, integral component of the doing of public engagement. On this score, by deploying a modified version of Stengers' figure of the idiot (the non-participant who makes no sense), the typical parameters of science communication could be interrogated.

This perspective was operationalised through a reflection upon a specific instance of science communication - the installation 'Landscape of Expectations'. In particular, we traced how idiotic behaviour, for example, being silly or leaving indecipherable or rude marks at the site of the 
installation, rather than making no sense, allowed us to query the presuppositions that fed into the design of the installation and the practice of science communication. As such, we began to explore how science communication might take note of idiotic actions and responses in ways that might serve in the de-sanitization of its tidy accounts of diffusion or dialogue. Thus, the idiotic behaviours of teenage girls exemplify the role of humour and play-acting in everyday life, and enable reflection on the implications of this for the practice of science communication, and public engagement more broadly, not least in relation to the conditionality of the seriousness they presuppose. We also discussed how the science communicators cannot avoid sanitizing the events in order to keep some form of meaningful coherence. Even a very inclusive communication event will require that the communicators strategically patrol its boundaries. The important conclusion in this context is for communicators to accept responsibility for these framings and the way in which they produce certain public voices.

However, this should not lead us to think of science communication as something that is at the discretion of the science communicators, since they will always be dependent on the audiences to participate. In the example discussed here, this dependency led to a profound sense of fragility on the part of the communicator. Other, more experienced, science communicators might have found ways of reducing this dependency in order to minimize the risk of the communication event producing un-expected outcomes. The central point of this paper, though, is that the fragility and dependence give rise to valuable insights which improve our understanding of the event along the lines of the model of emergence.

Our suggestion is that the framework of event and idiotic behaviour should be used as a tool for an on-going critical review of science communication and engagement processes. A key implication of the perspective is that the public space of science communication is marked by profound heterogeneity and contingency. Very different elements and relations 'become together' 
in the event of science communication, and which ones actually do become together is a matter of profound contingency. The notion of event can sensitize researchers to the conditions of science communication; and the figure of the idiot can facilitate a probing of researchers' own enactment of such events. Central to this sensitivity is that researchers appreciate the fragility of the actors of science communication and abstain from sanitizing the science communication event by purging it of all marks of idiotic behaviour. Instead they should embrace these because they throw light on the very contingency of the event.

One upshot is that science communication takes on a far more 'processual' complexion. Diffusion and deliberation models tend toward the production of solutions. Respectively, these solutions might address the lack of scientific knowledge amongst lay publics, and the limitations of dialogic procedures. By contrast, the model of emergence aims to generate inventive problems which stimulate further exploration and analysis. The idiot does not simply facilitate the querying of the particular science communication event, but prompts reflection on science communication per se: that is to say, there is an ongoing rethinking of what it means to do science communication. Having made this programmatic statement, as we have seen above, this does not preclude recourse to diffusion or deliberation models in the design of science communication events. The key point is that these are constantly under scrutiny. However, this scrutiny should go beyond standard forms of academic reflection and include the unexpected sort of questioning prompted by various idiotic behaviours.

There are, inevitably, further aspects of this event-oriented understanding of science communication that can benefit from further elaboration. We take note of two here. Firstly, there is the issue of the space-time borders of the event. Is the installation one event over the course of its residency in the shopping centre? Was 'it' a linear series of events that were realised as different visitors came and went? Was 'it' a melange of events depending on the complex multiple and 
simultaneous combinations of parts of the installation and aspects of different visitors? On one, rather abstract, level, this raises the issue of the models of temporality we might wish to append to our version of the event. More interestingly, it suggests that we need to reflect on how the deployment of different temporal parameters of the event gesture in different rhetorical or political directions.

Secondly, we have treated the figure of the idiot as an empirical (and metaphysical) thorn in our analytic side. And yet, as soon as we deploy it in this way we tame it: at the very least, there is a prospect of 'self-satisfaction' in our own analytic discomfort. Moreover, such taming also entails forms of judgment: there is always the danger that we only draw upon those idiots that best suit us in our analytic self-critique. It behoves us, then, to learn how to keep animated the interplay between metaphysical and empirical idiots.

The idiot, however, is not exclusive to academics’ engagement with publics - it is present in everyday life. The idiots of Landscape of Expectations were, arguably, themselves subjected to the idiocy of Landscape of Expectations. The installation could challenge them just as much as they could challenge its organisers and analysts. Ironically, in the midst of this 'mutual idiocy' lie the prospect of mutual change and a more inclusive version of science communication. But for this prospect to be realised, we have to find ways of seeking the excluded, making sense of the non-sensical and learning from the incomprehensible. In other words, when performing and analysing events of science communication, we have to find ways of climbing onto the shoulders of idiots. 


\section{References}

Andersen, I.-E. \& Jæger, B. (1999) Danish participatory models. Scenario workshops and consensus conferences: towards more democratic decision-making. In Science and Public Policy, 26 (5) pp. 331-340.

Bauer, M. \& Gaskell, G. (eds.) (2002) Biotechnology. The making of a Global Controversy. Cambridge University Press, Cambridge.

Bijker, W. E. \& Law, J. (eds.) (2000) Shaping Tecnology/Building Society. MIT Press, Cambridge, Massachusetts, London.

Brown, N., Rappert, B., \& Webster, A. (2000) Introducing contested futures: from Looking into the future to looking at the future. In Brown, N. et al (eds) Contested Futures: A sociology of prospective techno-science. Ashgate, Aldershot, pp. 3-20.

Callon, M. (ed.) (1998) The Laws of the Markets. Blackwell Publishers, Oxford.

Davies, Sarah R. (2009) 'Doing Dialogue: Genre and Flexibility in Public Engagement with Science', In Science as Culture, 18 (4) pp. 397 - 416

Douglas, M.(1996a) Risk and blame - Essays in cultural theory. Routledge, London.

Douglas, M.(1996b) Thought Styles. SAGE, London.

Douglas, M.(2001) Natural symbols - Explorations in cosmology. Routledge, London.

Douglas, M. \& Wildavsky, A.(1983) Risk and culture. University of California Press, Berkeley. 
Edwards, A. (1999) Scientific expertise and policy-making: the intermediary role of the public sphere. In Science and Public Policy, 26 (3) pp. 163-170.

Einsiedel, E. F. \& Eastlick, D. L. (2000) Consensus conferences as deliberative democracy. In Science Communication, 21 (4) pp. 323-343.

Einsiedel, E. F., Jelsøe, E., \& Breck, T. (2001) Publics at the technology table: the consensus conference in Denmark, Canada, and Australia. In Public Understanding of Science, 10 (1) pp. 8398.

Fischer, F. (1999) Participatory inquiry. Technological deliberation in a democratic society: the case for participatory inquiry. In Science and Public Policy, 26 (5) pp. 294-302.

Fraser, M. (2010) 'Facts, Ethics and Event,' in C. Bruun Jensen and K. Rödje (eds) Deleuzian Intersections in Science, Technology and Anthropology. New York: Berghahn Press, 57-82.

Garfinkel, H. (1967). Studies in Ethnomethodology, Cambridge: Polity Press.

Hagendijk, R. \& Irwin, A. (2006) Public deliberation and governance: Engaging with Science and technology in contemporay Europe. In Minerva, 44 (Volume 44, Number 2 / June, 2006) pp. 167184.

Hall, S (1980) Encoding/Decoding in Hall, S et al (eds): 'Culture, Media, Language’. Hutchinson, London.

Horst, M. (2003) Controversy and Collectivity - Articulations of social and natural order in mass mediated representations of biotechnology. Copenhagen Business School, Doctoral School on knowledge and management. 
Horst, M. (2005) Cloning Sensations: mass mediated articulation of social responses to controversial biotechnology. In Public Understanding of Science, 14 (2) 185-200.

Horst, M. (2007) Public expectations of gene therapy: scientific futures and their performative effects on scientific citizenship. In Science, Technology \& Human Values, 32 (2) 150-171.

Horst, M. (2008a) In search of dialogue: staging science communication in consensus conferences. In Cheng, D. et al: 'Communicating science in social contexts'. Springer, pp. 259-274.

Horst, M. (2008b) The laboratory of public debate: understanding the acceptability of stem cell research. In Science and Public Policy, 35(3), 2008.

Irwin, A.(1995) Citizen science. A study of people, expertise and sustainable development. Routledge, London.

Irwin, A. (2006) The politics of talk: Coming to terms with 'new' scientific governance. In Social studies of science, 36 (2) pp. 299-322.

Irwin, A. \& Michael, M.(2003). Science, social theory and public knowledge. Maidenhead: Open University Press.

Irwin, A. \& Wynne, B.(1996) Misunderstanding Science? Press Syndicate of the University of Cambridge, Cambridge.

Jensen, C. B. (2005) Citizen projects and consensus-building at the Danish board of technology On experiments in democracy. In Acta Sociologica, 48 (3) pp. 221-235.

Joss, S. (1999) Introduction. Public participation in science and technology policy - and decisionmaking - ephemeral phenomenon or lasting change? In Science and Public Policy, 26 (5) pp. 290293. 
Joss, S. (2002) Toward the Public sphere - Reflections on the Development of Participatory Technology Assessment. In Bulletin of Science, Technology \& Society, 22 (3) pp. 220-231.

Latour, B.(1987) Science in action. Harvard University Press, Massachusetts.

Latour, B. \& Woolgar, S.(1979) Laboratory Life. The construction of scientific facts. Princeton University Press, New Jersey.

Law, J.(ed) (1986) Power, Action and Belief. Routledge, London.

Law, J. \& Hassard, J. (eds) (1999) Actor Network Theory and After. Blackwell Publishers, Oxford.

Levidow, L. \& Marris, C. (2001) Science and governance in Europe: lessons from the case of agricultural biotechnology. In Science and Public Policy, 28 (5) pp. 345-360.

Lezaun, Javier \& Linda Soneryd (2007) 'Consulting citizens: technologies of elicitation and the mobility of publics’, Public Understanding of Science 16 (3) pp. 279-297.

Michael, M. (2002) Comprehension, Apprehension, Prehension: Heterogeneity and the Public Understanding of Science. In Science, Technology, \& Human Values, 27 (3) pp. 357-378.

Rogers, E. M.(1995) Diffusion of Innovation. Free Press, New York.

Serres, M. (1982). The Parasite, Baltimore: Johns Hopkins University Press.

Stengers, I. (2005) The Cosmopolitical Proposal. In B. Latour and P. Webel (eds), Making Things Public Cambridge, Mass.: MIT Press pp. 994-1003.

Van Lente, H.(1993) Promising Technology: The Dynamics of Expectations in Technological Developments. University of Twente, 
Wilsdon, J, Wynne, B, \& Stilgoe, J, (2005) The Public Value of Science - Or how to ensure that science really matters (London: Demos).

Wynne, B. (2005) Risk as globalizing 'democratic' discourse? Framing subjects and citizens. In

Leach, M. et al: 'Science and Citizens'. Zed Books, London, pp. 66-82.

\footnotetext{
${ }^{\text {i }}$ Although we do not explicate this in detail here, the figure of the idiot is tied to Stengers' (2005) concept of 'cosmopolitics' in which there is an 'eventful' bringing and becoming together of various actors/elements. Crucially, cosmopolitics adds an additional element of caution: that we as analysts/designers of the science communication event should take 'fright' at any self-assurance we have about the event of science communication. Our grasp of the event is tenuous at best. In addition, the idiot can be likened to Michel Serres (1982) notion of the 'excluded third' - that which must be excluded in order for meaning and order making to be possible. Yet, according to Serres, such disturbances open up the space for new meanings and introduce a potential for generating more complex orders.

${ }^{\text {ii }}$ Our version of the idiot clearly ends up (partially) taming it, which of course is untenable for what is a metaphysical principle. The idiot is always present and will always necessarily escape. As soon as we manage to tame the particular idiotic act, idiocy necessarily re-asserts itself to confound and confuse us.

${ }^{\text {iii }}$ The beads had colour codes, which allowed us to see that this was indeed the case.

${ }^{\text {iv }}$ This has been a common point of discussion among Danish academics.

${ }^{\mathrm{v}}$ The Youth House was a property, the use of which was offered to the loosely organized group of young people engaged in squatter activities in the 1980's by the Copenhagen Municipality. The ownership was later transferred to a private organization and following an extended period of negotiations, legal battles and street riots, the house was demolished under massive police protection in 2007.
} 